\title{
UMA METODOLOGIA BASEADA EM INDICADORES DE DESEMPENHO PARA AVALIAÇÃO DA IMPLANTAÇÃO DA MANUFATURA ENXUTA: PROPOSTA E ESTUDO DE CASO
}

\section{A METHODOLOGY BASED ON PERFORMANCE INDICATORS TO EVALUATE LEAN MANUFACTURING IMPLEMENTATION: PROPOSAL AND CASE STUDY}

\footnotetext{
Flávio Teodoro Dias ${ }^{1}$; Flavio Cesar Faria Fernandes ${ }^{2}$; Moacir Godinho Filho ${ }^{3}$

${ }^{1}$ Universidade Federal de São Carlos - São Carlos - Brasil - flavio@braile.com.br

${ }^{2}$ Universidade Federal de São Carlos - São Carlos - Brasil - dfcf@power.ufscar.br

${ }^{3}$ Universidade Federal de São Carlos - São Carlos - Brasil - moacir@dep.ufscar.br
}

\begin{abstract}
Resumo
A Manufatura Enxuta (ME) é um paradigma de Gestão que objetiva a redução de desperdicios. Apesar de bastante conhecida e intuitivamente relacionada à melhoria de performance, existe na literatura um questionamento quanto ao entendimento da ME como "best practice". Diante disso, há a necessidade de se avaliar os ganhos potenciais, com relação ao aumento da competitividade, da ME. O presente trabalho contribui exatamente neste sentido, pois apresenta a proposta de uma metodologia inédita baseada em indicadores de desempenho enxutos (a maioria dos indicadores de desempenho tradicionais não se prestam à avaliação da ME) para a avaliação da implantação da ME em empresas, facilitando o comprometimento e o sucesso da implementação da ME. Tal metodologia auxilia a empresa a escolher corretamente indicadores de desempenho enxutos em função de três características: objetivos da implantação da ME, abrangência da implantação (chão de fábrica, empresa ou cadeia de suprimentos) e grau de implantação dos princípios enxutos. A metodologia é aplicada em uma grande empresa do setor de equipamentos e instrumentos médicohospitalares.
\end{abstract}

Palavras Chave: Manufatura Enxuta, avaliação de implantação, indicadores de desempenho, estudo de caso, equipamentos médico-hospitalares.

\section{Introdução}

Manufatura Enxuta (ME) é definida por Womack \& Jones (1998) como sendo uma abordagem segundo a qual existe uma forma melhor de organizar e gerenciar os relacionamentos de uma empresa com os clientes, cadeia de fornecedores, desenvolvimento de produtos e operações de produção. Dentro desta abordagem tenta-se fazer cada vez mais com menos recursos (menos 
equipamento, menos esforço humano, menos tempo, etc...). $\mathrm{O}$ presente trabalho trata deste paradigma, apresentando uma metodologia baseada em indicadores de desempenho para a avaliação da eficácia e eficiência da implantação da Manufatura Enxuta.

$\mathrm{Na}$ literatura sobre ME existe um questionamento da ME como panacéia (Oliver et al, 1996; Bamber \& Dale, 2000; Lewis, 2000). Portanto é necessário a avaliação da contribuição da ME com o aumento da competitividade das empresas. Esta avaliação deve se dar em função de cada situação, uma vez que cada implantação da ME pode seguir um caminho diferente, com a utilização de diferentes princípios (Panizzolo, 1998; Allen, 2000). É dentro deste contexto que este trabalho pretende contribuir, apresentando uma metodologia para escolha de indicadores para a ME com a finalidade de avaliar a implantação da ME em empresas. A escolha de indicadores é baseada em três características: objetivos e abrangência da implantação e grau de implantação dos princípios. Com relação aos objetivos os indicadores escolhidos devem medir a evolução da empresa nos objetivos de desempenho da produção priorizados pela empresa. Referente à abrangência da implantação, a escolha de indicadores é influenciada por três possíveis abrangências, propostas por Godinho Filho \& Fernandes (2004), a saber: chão de fábrica, empresa e cadeia de suprimentos. A abrangência empresa se refere aos princípios relacionados a outras áreas da empresa que não especificamente o chão de fábrica, como o projeto, recursos humanos, finanças, etc. (Godinho Filho \& Fernandes, 2004). Finalmente o grau de implantação dos princípios enxutos define se serão utilizados dados reais (quando os princípios já estão implantados) ou simulação (quando se está estudando a implantação dos princípios enxutos) para avaliar a ME.

Como podemos notar, um ponto fundamental da metodologia de avaliação da ME é a utilização de indicadores de desempenho. Segundo Neely et al. (1995), a medição do desempenho é um assunto freqüentemente discutido, mas raramente definido. Para ele, a medição do desempenho pode ser definido como o processo de se quantificar a eficiência e a eficácia de uma ação; já um sistema de medição de desempenho pode ser definido como um conjunto de medidas utilizadas para se quantificar a eficiência ou eficácia de uma ação.

De acordo com Shemenner \& Vollmann (1994) dois problemas principais ocorrem com relação à utilização de indicadores de desempenho: i) a utilização de indicadores inadequados, que conduzem ao dispêndio de tempo pelos gerentes tentando melhorar alguma coisa que tem pouco impacto no resultado da empresa; ii) a não utilização de indicadores chave, fazendo com que algum fator importante para a empresa seja desprezado. Também para Martins \& Costa Neto (1998) os sistemas tradicionais de medição, tendo como principal preocupação a medição em termos de uso eficiente de recursos, são inadequados frente às novas tecnologias, às novas formas de organização da produção e aos novos conceitos e filosofias da administração. Este é exatamente o caso da 
Manufatura Enxuta. Falta a este novo paradigma um sistema de avaliação de desempenho consistente e que principalmente seja de fácil aplicação prática.

A metodologia apresentada se presta exatamente a eliminar o alarme falso, causado pelo erro (i) descrito, auxiliando na escolha de um conjunto completo de indicadores que preencham as lacunas ocasionadas pelo erro (ii).

A metodologia proposta é aplicada em um estudo de caso em uma grande empresa do setor de fabricação de equipamentos e instrumentos médico-hospitalares. Esta aplicação mostra que a metodologia é simples, de fácil compreensão e aplicação por gerentes da produção. Estas são exatamente características que metodologias de Gestão da Produção devem ter a fim de contribuir com a redução da lacuna entre a teoria e prática na área (MacCarthy \& Liu, 1993 e Nam \& Logendran, 1992). Especificamente para a empresa, a aplicação da metodologia serviu para a avaliação do princípio da produção puxada da ME, o qual a empresa já tem implementado.

O estudo de caso, segundo Eisenhardt (1989), pode cumprir os seguintes objetivos: i) fornecer descrição sobre um tema; ii) testar a teoria; iii) gerar teoria. No presente trabalho, o objetivo do estudo de caso é o de testar a teoria gerada.

A estrutura do trabalho é a que segue: na próxima seção são apresentados indicadores de desempenho que podem ser utilizados na ME; na seção 3 é proposta a metodologia propriamente dita; na seção 4 a metodologia é testada em um estudo de caso em uma empresa que fabrica equipamentos médico hospitalares e na seção 5 são tecidas algumas conclusões.

\section{Indicadores de desempenho para a Manufatura Enxuta}

Nesta seção o trabalho apresenta, a partir de uma revisão da literatura, indicadores de desempenho que podem ser utilizados na ME. Sánchez \& Pérez (2001) apresentam um check-list contendo um número de 36 indicadores enxutos encontrados na literatura. Este trabalho segue o modelo proposto por Karlsson \& Ahlström (1996), que visa contribuir de uma maneira empírica com o estudo dos indicadores de desempenho relativos ao ambiente da ME.

Sánchez \& Pérez (2001) relacionam seis grupos de indicadores, cada um relacionado a um importante princípio enxuto, a saber: i) eliminação das atividades que não agregam valor; ii) melhoria contínua; iii) equipes multifuncionais; iv) produção e entrega just in time; v) integração de fornecedores; vi) sistemas de informação flexíveis.

Detty \& Yingling (2000) também apresentam um conjunto de indicadores para a ME. Alguns destes indicadores são: tempo de fila, espaço físico, tempo de fluxo médio, dentre outros. 
Também Shah \& Ward (2002) trabalham com este aspecto de avaliação da ME por meio de indicadores de desempenho.

A partir destes trabalhos apresentamos (quadros 1,2 e 3) os indicadores de desempenho para a ME. Estes indicadores foram devidamente divididos de acordo com a abrangência do indicador com relação às três possíveis abrangências de implantação da ME (chão de fábrica, empresa e cadeia de suprimentos). A justificativa para estas três abrangências reside no fato de que apesar de ter nascido no chão de fábrica, como o próprio nome mostra, a ME evoluiu nos dias atuais para outras áreas da cadeia de suprimentos. Nas palavras de Warnecke \& Hüser (1995): “a produção propriamente dita é somente um dos aspectos da ME”. Para Panizzolo (1998), alguns autores, em razão do aumento de escopo da ME, chegaram a sugerir o termo Empresa Enxuta ao invés de somente Manufatura Enxuta.

Neste artigo mostra-se (figura 1) como os mais importantes e conhecidos princípios da ME se distribuem ao longo das três abrangências (chão-de-fábrica, empresa e cadeia de suprimentos). A abrangência da implantação da ME é uma das características que influencia na escolha dos indicadores de desempenho, como será mostrado na próxima seção. 
FIGURA 1: Os princípios enxutos relacionados às três abordagens da ME

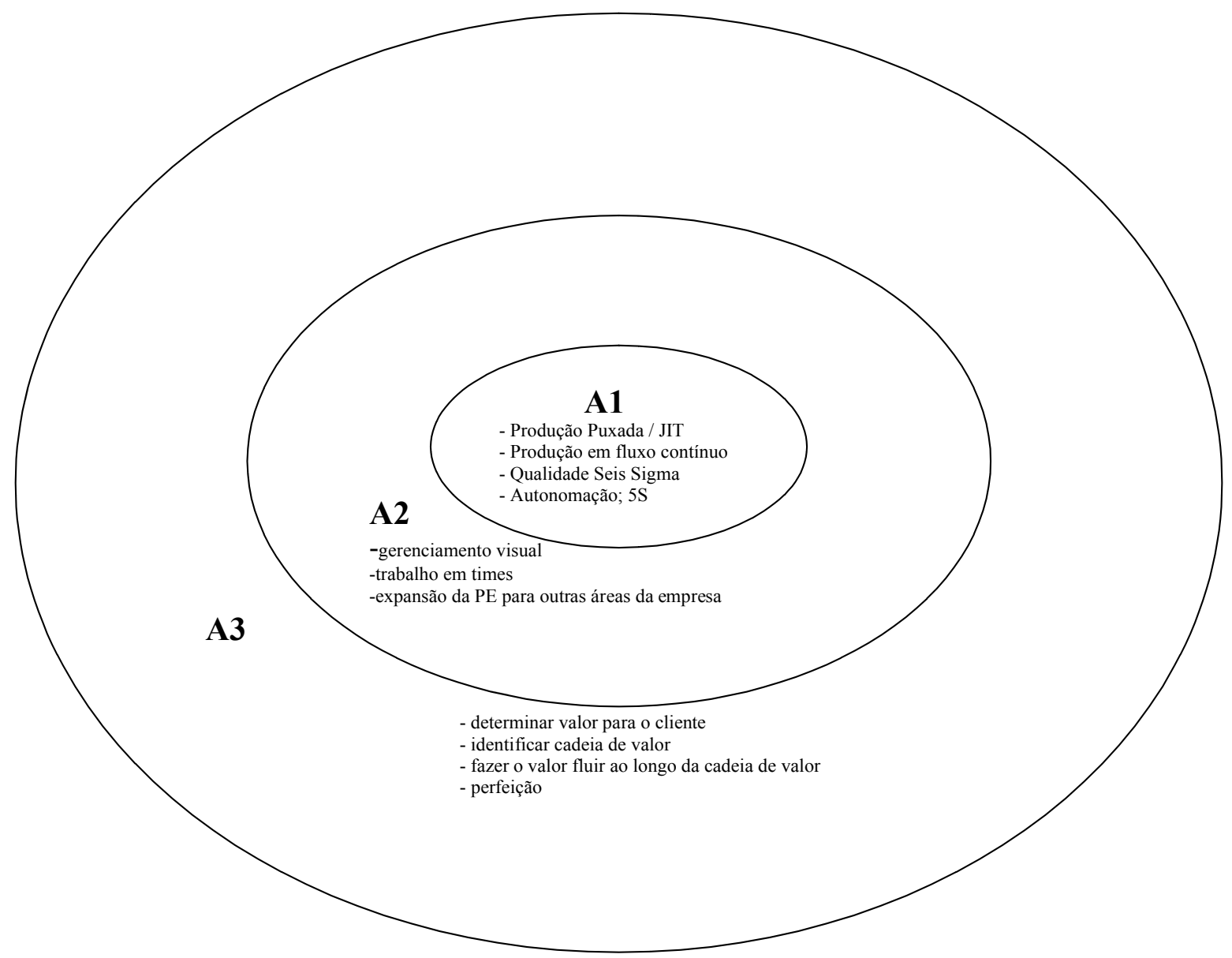

A1 - Chão de fábrica

A2 - Empresa

A3 - Cadeia de suprimentos

Fonte: Autoria própria 
Quadro 1: Indicadores para medir o desempenho da Manufatura Enxuta no chão de fábrica

Quantidade de tempo necessário para alterações na linha de produção (tempo de set up)

Tamanho dos lotes de produção

Quantidade de estoque em processo/Tempo de fila

Tempo de fluxo médio

Número de vezes e distância percorrida pelas peças no chão de fábrica

Necessidade de espaço físico no chão de fábrica

Percentual de manutenção preventiva sobre a manutenção total

Percentual das inspeções realizadas por meio do controle autônomo de defeitos

Percentual de peças defeituosas corrigidas pelos trabalhadores na própria linha

Número de horas-máquina parada devido a quebras em relação ao total do tempo da máquina

Custo/Tempo de refugo e retrabalhos

Custo unitário de produção

Produtividade de mão de obra

Número de pessoas dedicadas a atividades de controle de qualidade

Número de pessoas no chão de fábrica

Utilização de meio de transporte de materiais no chão de fábrica

Percentual de peças entregue just- in- time entre seções da produção

\section{Fonte: Autoria Própria}

Quadro 2: Indicadores para medir o desempenho da Manufatura Enxuta na empresa

Percentual de peças comuns nos produtos da empresa

Valor do estoque em processo em relação ao valor das vendas

Giro anual de estoque

Número de sugestões dos empregados

Percentual das sugestões implementadas

Economia ou benefícios das sugestões

Valor do refugo/retrabalho em relação às vendas

Percentual dos empregados trabalhando em equipes

Número e porcentagem de tarefas realizadas pelas equipes

Percentual de empregados que realizam várias tarefas na empresa

Freqüência média da rotação das tarefas

Percentual dos líderes de equipes que são eleitos por sua própria equipe de trabalho

Freqüência com que as informações são repassadas aos empregados

Número de reuniões informativas entre os gerentes e os empregados

Percentual de procedimentos escritos arquivados na empresa

Percentual de equipamentos de produção integrados por computador

Número de decisões que os empregados podem tomar sem controle do supervisor

Fonte: Autoria Própria

Quadro 3: Indicadores para medir o desempenho da Manufatura Enxuta na cadeia de suprimentos

Lead time dos pedidos dos clientes

Percentual das peças entregues just-in-time pelos fornecedores

Nível de integração entre as entregas dos fornecedores e o sistema de controle de produção da empresa

Percentual de peças e componentes projetados em parceira com os fornecedores

Número de sugestões realizadas pelos fornecedores

Freqüência com que os técnicos dos fornecedores visitam a empresa

Freqüência com que os fornecedores são visitados por técnicos da empresa

Percentual de documentos trocados com os fornecedores por meio de EDI (transferência eletrônica de dados) ou

Intranet

Duração média dos contratos com os mais importantes fornecedores

Número médio de fornecedores para as peças mais importantes

Fonte: Autoria Própria 


\section{A Metodologia proposta}

A metodologia proposta objetiva a escolha dos indicadores para a ME (descritos na seção anterior) a serem utilizados pela empresa. Esta escolha se dá em função de três características: i) foco nos objetivo de desempenho da produção priorizados pela empresa; ii) abrangência dos princípios utilizados na empresa; iii) grau de implantação dos princípios na empresa. A definição do grau de implantação define a utilização de dados reais ou simulados; caso o princípio já esteja implantado, pode-se utilizar dados reais; caso o sistema não esteja implantado, os dados utilizados serão obtidos por simulação. Devido a este foco no grau de implementação dos princípios, a metodologia, além de servir para a avaliação da ME já implementada em uma empresa, também se presta à avaliação da ME ainda antes de sua implementação, ou seja, ajuda a gerência a responder uma importante e difícil questão: A ME é realmente a estratégia mais adequada para a empresa ?

Mais especificamente, a metodologia para a escolha de indicadores para a ME é um algoritmo com 5 passos que analisam as três características citadas acima. Este algoritmo é descrito a seguir e ilustrado na figura 2 .

\section{PASSO 1 - Identificar o objetivo principal a ser focado pela ME}

A ME é um paradigma que contribui principalmente com melhorias nos objetivos qualidade e produtividade (Fernandes \& Maccarthy, 1999; Godinho Filho, 2004). Neste passo inicial da metodologia deve-se definir quais serão os objetivos principais que são esperados com relação à implementação de princípios da $\mathrm{ME}$, ou seja, se a aplicação dos princípios visa a melhoria dos objetivos da manufatura qualidade ou produtividade separadamente, ou ambos ao mesmo tempo. A escolha dos indicadores deve ser feita em função dos objetivos definidos neste passo.

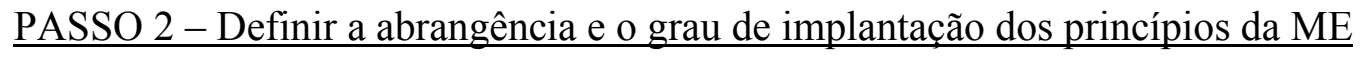

Já citamos anteriormente que a implementação da ME pode seguir um caminho diferente, com a utilização de diferentes princípios. A avaliação da ME por meio de indicadores de desempenho se dá por meio da avaliação dos princípios implementados ou a serem implementados da Manufatura Enxuta. Portanto temos que duas questões são vitais na escolha dos indicadores de desempenho para a ME: i) a abrangência dos princípios (chão de fábrica, empresa e cadeia de suprimentos) da ME que serão avaliados; ii) o grau de implantação destes princípios (princípios já implementados ou ainda a serem implementados).

A partir da junção do resultado destas duas questões teremos seis situações as quais serão a base para a escolha de indicadores de desempenho para a ME. A primeira situação (denominaremos situação 1) é aquela cuja abrangência dos princípios da ME é o chão de fábrica e 
os princípios enxutos já se encontram implementados (e portanto podem ser utilizados os dados reais na avaliação). Também a situação 2 é relativa à abrangência chão de fábrica, porém nesta situação a implantação da ME ainda encontra-se em fase de estudo e portanto os princípios ainda não se encontram implementados. Tem-se então que na situação 2 é necessário a utilização da simulação para a avaliação do desempenho da ME. As situações 3 e 4 são relativas a princípios da ME na empresa; enquanto a situação 3 se refere a princípios já implementados (dados reais podem ser utilizados), na situação 4 os princípios ainda não estão implementados e a simulação se faz necessária. A mesma idéia é válida para as situações 5 (dados reais) e 6 (dados simulados), porém a abrangência nestas duas situações é a cadeia de suprimentos.

\section{PASSO 3 - Escolher os indicadores de desempenho mais apropriados para cada situação}

Nesta etapa são definidos os indicadores a serem utilizados na avaliação da ME. Para cada situação, definida no passo 2, são sugeridos indicadores mais apropriados. Vale a pena algumas observações importantes a respeito da escolha dos indicadores mais apropriados para cada situação:

- Os indicadores de desempenho para cada uma das três abordagens são os indicadores extraídos da literatura e mostrados nos quadros 1,2 e 3.

- Os indicadores adequados para as situações 2, 4 e 6 (situações nas quais os princípios ainda não se encontram implantados e a avaliação deve se dar por meio de simulação) foram sugeridos por meio de uma análise de trabalhos que já utilizaram estes indicadores por meio da simulação dentro do contexto da ME. Exemplos destes trabalhos são: Detty \& Yingling (2000); Lummus (1995); Galbraith \& Standridge (1994).

- Para a abrangência no chão de fábrica, acreditamos que os indicadores de desempenho não têm a mesma importância para a medição das melhorias trazidas pela $\mathrm{ME}$, sendo que, em alguns casos, somente por meio da verificação de melhorias em um indicador é que sensíveis melhorias poderão ser alcançadas em outro indicador. Portanto tentamos apresentar os indicadores adequados para as situações 1 e 2 (relativas ao chão de fábrica) de acordo com uma ordem de importância. Um indicador é entendido como mais importante quanto maior for o impacto que ele causa nos outros indicadores. Por exemplo, para a situação 1, o primeiro indicador que é citado é a redução dos tempos de set up, indicador este que se caracteriza como sendo o mais importante em nível de chão de fábrica, uma vez que é somente por meio de melhorias neste indicador que serão possíveis melhorias sensíveis em outros indicadores tais como tamanho de lote de produção, quantidade de estoque em processo e tempo médio de fluxo. 
Para a situação 1 (abrangência chão de fábrica e princípios já implementados) recomendamse, por ordem de prioridade, os seguintes indicadores:

$>$ Tempo de set up

$>$ Tamanho de lote de produção

$>$ Percentual de peças entregue just in time entre seções da produção

$>$ Número de vezes e distância percorrida pelas peças no chão de fábrica

$>$ Necessidade de espaço físico no chão de fábrica

> Utilização de meios de transporte de materiais no chão de fábrica

$>$ Percentual de inspeções realizadas pelo controle autônomo de defeitos

$>$ Percentual de peças defeituosas corrigidas pelos trabalhadores na própria linha

$>$ Número de trabalhadores dedicados à atividade de controle de qualidade

$>$ Percentual de manutenção preventiva sobre a manutenção total

$>$ Número de horas-máquina paradas devido a quebras em relação ao total de horasmáquina

$>$ Custo/Tempo de refugo e retrabalho

$>$ Quantidade de estoque em processo/Tempo de fila

$>$ Tempo de fluxo médio

$>$ Número de pessoas no chão de fábrica

$>$ Produtividade de mão de obra

$>$ Custo unitário de produção

Para a situação 2 (abrangência chão de fábrica e princípios ainda não implementados) recomendam-se, por ordem de prioridade, os seguintes indicadores:

- Tempo de set up

- Tamanho de lote de produção

- Necessidade de espaço físico no chão de fábrica

- Utilização de meios de transporte de materiais no chão de fábrica

- Quantidade de estoque em processo/Tempo de fila

- Tempo médio de fluxo

- Número de pessoas no chão de fábrica

- Produtividade de mão de obra

Para a situação 3 (abrangência empresa e princípios já implementados) recomendam-se os seguintes indicadores:

- Percentual de peças comuns nos produtos da empresa 
- Valor do estoque em processo em relação ao valor das vendas

a Giro anual de estoque

口 Número de sugestões dos empregados

a Percentual das sugestões implementadas

a Economia ou benefícios das sugestões

口 Valor do refugo/retrabalho em relação às vendas

口 Percentual dos empregados trabalhando em equipes

- Número e porcentagem de tarefas realizadas pelas equipes

a Percentual de empregados que realizam várias tarefas na empresa

- Freqüência média da rotação das tarefas

a Percentual dos líderes de equipes que são eleitos por sua própria equipe de trabalho

- Freqüência com que as informações são repassadas aos empregados

- Número de reuniões informativas entre os gerentes e os empregados

a Percentual de procedimentos escritos arquivados na empresa

- Percentual de equipamentos de produção integrados por computador

a Número de decisões que os empregados podem tomar sem controle do supervisor

Para a situação 4 (abrangência empresa e princípios ainda não implementados) recomendam-se os seguintes indicadores:

$\checkmark$ Valor do estoque em processo em relação ao valor das vendas

$\checkmark$ Giro anual de estoque

$\checkmark$ Freqüência média da rotação das tarefas

Para a situação 5 (abrangência cadeia de suprimentos e princípios já implementados) recomendam-se os seguintes indicadores:

* Lead time dos pedidos dos clientes

* Percentual das peças entregues just-in-time pelos fornecedores

* Nível de integração entre as entregas dos fornecedores e o sistema de controle de produção da empresa

* Percentual de peças e componentes projetados em parceira com os fornecedores

* Número de sugestões realizadas pelos fornecedores

* Freqüência com que os técnicos dos fornecedores visitam a empresa

* Freqüência com que os fornecedores são visitados por técnicos da empresa

* Percentual de documentos trocados com os fornecedores por meio de EDI (transferência eletrônica de dados) ou Intranet 
* Tamanho médio dos contratos com os mais importantes fornecedores

* Número médio de fornecedores para as peças mais importantes

Para a situação 6 (abrangência cadeia de suprimentos e princípios ainda não implementados) recomenda-se o seguintes indicador:

- Lead time dos pedidos dos clientes

\section{$\underline{\text { PASSO } 4 \text { - Calcular os valores dos indicadores }}$}

Após serem definidos os indicadores a serem utilizados em função dos objetivos, e cada uma das seis situações, como visto nos passos anteriores, devem ser calculados os valores destes indicadores.

\section{PASSO 5 - Análise dos indicadores}

Neste último passo os resultados são analisados e pode-se desta forma avaliar a implantação da ME na empresa verificando-se se a ME está realmente contribuindo (ou irá contribuir) para a melhoria da competitividade da empresa.

A figura 2 ilustra a metodologia descrita. 
Figura 2 - Metodologia para avaliação de performance de um sistema de Manufatura Enxuta

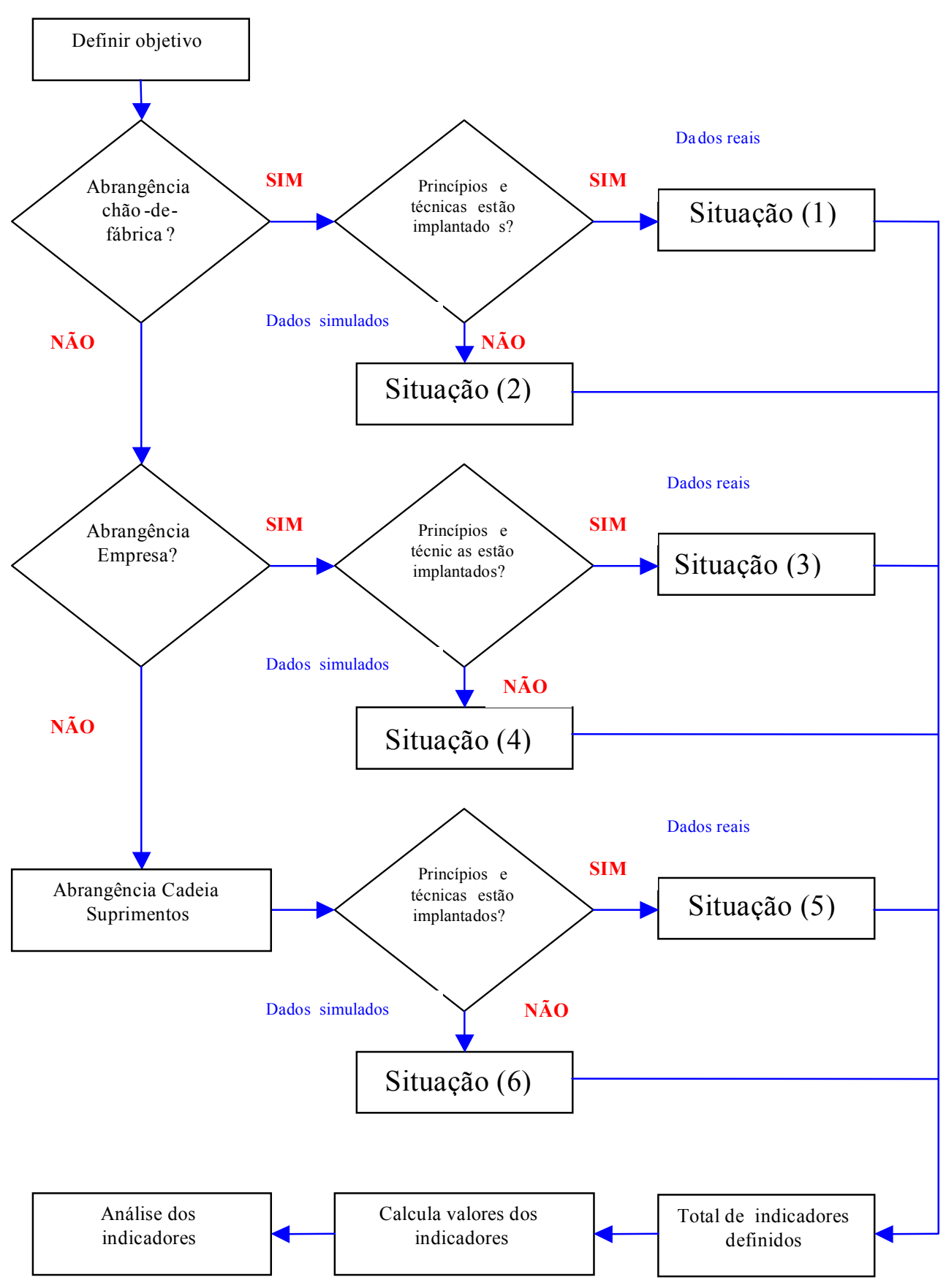

Fonte: Autoria Própria

\section{A aplicação da metodologia}

O estudo de caso é aplicado em uma indústria da cadeia médico hospitalar fabricante de próteses valvares, endopróteses, equipamentos eletromédicos e produtos descartáveis utilizados na área de cirurgia cardíaca. Aproximadamente 250 tipos de produtos formam o mix de produção da 
empresa, a qual conta com aproximadamente 350 funcionários. A empresa está posicionada como uma das sete maiores produtoras de oxigenadores do mundo e exporta $15 \%$ de sua produção para mais de 21 países.

A empresa está iniciando a implantação da ME. O princípio da ME que se encontra implantado em alguns setores da empresa (dentre eles a injeção) é o da produção puxada/JIT, com a utilização do kanban. A aplicação da metodologia visa avaliar a implantação deste princípio da ME.

Dentre os princípios do paradigma enxuto, a produção puxada/JIT por meio do Kanban talvez seja um dos princípios que mais permita a visualização das vantagens obtidas pela incorporação de técnicas enxutas de produção, pois a sua utilização traz consigo a simplificação do fluxo, diminuição dos lotes de produção, redução do tempo de setup, controle da qualidade e do sequenciamento da produção por parte do operador, melhor aproveitamento dos materiais em processo e melhor organização do setor em relação à sua segurança, ordem e limpeza. Sendo assim este é um princípio bastante adequado à aplicação da metodologia. A seguir é mostrada a aplicação da metodologia na empresa, seguindo os passos mostrados na seção anterior.

PASSO 1: Quanto à definição de quais objetivos de desempenho são prioritários com relação à implementação da ME na empresa, temos que o foco principal da empresa é o objetivo produtividade, visto que o setor analisado (injeção) é crítico para o abastecimento da produção e sua rápida e eficiente resposta é um importante fator de vantagem competitiva.

PASSO 2: Neste passo definimos a abrangência e o grau de implantação dos princípios da ME, no caso a produção puxada/JIT. O princípio produção puxada/JIT está em nível de chão-de-fábrica, ao mesmo tempo em que já se encontra implantado, o que sugere a utilização de dados reais. Esta situação corresponde exatamente a situação 1 mostrada na figura 2.

PASSO 3: Neste passo são escolhidos indicadores de desempenho adequados para a situação encontrada no passo 2 (situação 1). A partir da lista de indicadores de desempenho sugeridos para a situação 1 procurou-se selecionar um indicador de maior importância e que ao mesmo tempo fosse de fácil obtenção na empresa. O indicador selecionado foi o tamanho dos lotes de produção. Este indicador atende as especificações, sendo considerado de alto grau de importância para o objetivo produtividade, aplicado ao chão-de-fábrica e permite a utilização de dados reais. Além disso, as informações disponíveis na empresa permitem a utilização deste indicador.

PASSO 4: Nesta etapa devemos calcular os valores do indicador escolhido, ou seja, valores referentes ao tamanho dos lotes de produção. Para isso, foi efetuada a coleta dos dados de tamanho 
de lote de produção nas etiquetas kanban existentes no setor de injeção para determinados moldes de injeção escolhidos aleatoriamente. A tabela 1 mostra o tamanho dos lotes de produção para 07 itens que serão os constituintes da amostra dos componentes que será objeto da avaliação.

TABELA 1 - Tamanho do lote de produção kanban

\begin{tabular}{|c|c|}
\hline Nr. molde injeção & Tamanho lote por etiqueta Kanban \\
\hline 03 & 1000 \\
\hline 10 & 2800 \\
\hline 14 & 1000 \\
\hline 18 & 1500 \\
\hline 20 & 5000 \\
\hline 33 & 4400 \\
\hline 96 & 250 \\
\hline
\end{tabular}

Fonte: Autoria Própria

Após isso, foi realizado um levantamento baseado no histórico de fichas de ordens de serviço (OS) que eram emitidas antes da adoção do sistema Kanban neste setor. Antes da implementação do Kanban, a emissão das ordens de serviço ocorria na forma de uma planilha, constando a descrição do molde, o número do molde e a quantidade mensal a ser produzida. A tabela 2 mostra os valores médios de produção mensal por molde de injeção.

TABELA 2 - Tamanhos do lote de produção com sistema de emissão de ordens de serviço.

\begin{tabular}{|c|c|}
\hline Nr. molde injeção & Programação média mensal de produção \\
\hline 03 & 2000 \\
\hline 10 & 10000 \\
\hline 14 & 2500 \\
\hline 18 & 3000 \\
\hline 20 & 11000 \\
\hline 93 & 5000 \\
\hline 96 & 1500 \\
\hline
\end{tabular}

Fonte: Autoria Própria

Com o sistema adotado de emissão de ordens de serviço, o seqüenciamento da produção era feito com base na experiência do encarregado do setor de injeção. A planilha emitida pelo departamento de Planejamento e Controle da Produção (PCP) apenas definia as quantidades a serem produzidas no mês, deixando a cargo do encarregado encontrar uma boa maneira de programar as trocas de molde e a entrada destes nas máquinas. Como uma boa maneira nem sempre era encontrada ocorriam faltas freqüentes no processo posterior que dita a demanda, implicando em constantes trocas de molde não programadas causadas pelas "urgências" de produção. Este fato também acarretava em perda de matéria-prima, pois uma considerável quantidade de material que permanecia na zona de aquecimento da injetora (quando os moldes a serem trocados utilizavam materiais diferentes) se transformavam em refugo. 
PASSO 5: Esta etapa faz a análise dos dados. A tabela 3 mostra o percentual de redução no tamanho dos lotes de produção antes e depois da incorporação do sistema Kanban na produção de injetados.

TABELA 3 - Comparação tamanhos lotes produção

\begin{tabular}{|c|c|c|c|}
\hline Nr. Molde injeção & Sistema emissão ordens serviço & Sistema Kanban & Percentual redução tamanho lote \\
\hline 03 & 2000 & 1000 & $50 \%$ \\
\hline 10 & 10000 & 2800 & $72 \%$ \\
\hline 14 & 2500 & 1000 & $60 \%$ \\
\hline 18 & 3000 & 1500 & $50 \%$ \\
\hline 20 & 11000 & 5000 & $55 \%$ \\
\hline 33 & 5000 & 4400 & $12 \%$ \\
\hline 96 & 1500 & 250 & $83 \%$ \\
\hline \multicolumn{2}{|r|}{ Fonte: Autoria Própria } \\
\hline
\end{tabular}

Com a implantação do princípio da ME produção puxada/JIT, pelo uso do kanban, obteve-se a redução no tamanho dos lotes de produção, a redução do nível de material em processo, a eliminação de desperdícios de matéria-prima (ver passo 4), a simplificação do controle da produção; por outro lado, dado o aumento do número de set ups foi necessário despender esforços no desenvolvimento e utilização de troca rápida de ferramentas. Vale observar que uma condição importante para a bem sucedida implantação do sistema kanban estava presente: o fluxo de materiais era relativamente simples.

A implantação do sistema Kanban na unidade de injetados merece um destaque: antes da adoção do sistema Kanban um grande esforço em controle de estoques, programação da produção, emissão de ordens de produção e controle de produção era despendido para conseguir com que a produção dos itens injetados conseguisse suprir a demanda do setor de montagem. $\mathrm{O}$ comprometimento dos trabalhadores era baixo, pois estes apenas recebiam as ordens de serviço e "faziam o trabalho", não se preocupando em dar sugestões sobre a seqüência do trabalho ou quaisquer outras iniciativas que pudessem vir a contribuir com a melhoria do fluxo das operações. Além disso era criado constantes atritos entre o setor de PCP, responsável pela emissão das ordens, e o setor de fabricação. Após a implementação, os trabalhadores constataram que o sistema seria gerenciado por eles próprios, o que fez com que o interesse pelo trabalho aumentasse. Com isso, passaram a se preocupar com a redução do refugo, manutenção dos moldes, redução no tempo de preparação das máquinas e diversas outras melhorias. A implantação do Kanban nesta área trouxe grandes avanços em relação à simplificação ainda maior do fluxo e aos ganhos de produtividade. Sendo assim, utilizando a metodologia de avaliação proposta, conseguiu-se medir por meio de representações quantificáveis das características dos processos utilizados, os resultados ao longo do tempo em relação à implementação de um dos princípios da ME selecionado para o estudo de caso. 


\section{Conclusões}

Atualmente, a maior parte dos indicadores utilizados para se medir a performance de um sistema de produção estão atrelados ao volume e ao ritmo de produção, estando calcados sobre princípios da manufatura em massa. Este fato constitui um problema de extrema importância, pois quando se migra do conceito de manufatura em massa para manufatura enxuta (ME), estes indicadores inadequados não são capazes de avaliar os benefícios da Manufatura Enxuta. Ao mesmo tempo, no atual ambiente competitivo, avaliar os benefícios da implantação de um novo paradigma (no caso a ME) é vital.

Dentro deste contexto o presente trabalho propõe uma metodologia baseada em indicadores de desempenho enxutos que servem para avaliar a eficácia e eficiência da implantação da Manufatura Enxuta. Esta metodologia é aplicada em um estudo de caso em uma empresa da cadeia médico hospitalar. A utilização da metodologia proposta deve permitir que a empresa visualize os esforços e os benefícios da implantação da Manufatura Enxuta, proporcionando um maior grau de comprometimento com relação à sua aplicação. A metodologia também se presta a manter o rumo do projeto de implementação, servindo para guiar os esforços necessários para se vencer os obstáculos que inevitavelmente tenderão a aparecer.

Como principal conclusão tem-se que os mecanismos de medição de desempenho apropriados para a Manufatura Enxuta em conjunto com a metodologia apresentada neste trabalho permitem monitorar a performance de uma empresa, ao mesmo tempo em que permitem estimular futuras ações.

Em face do exposto, podemos concluir que em uma implantação da ME os indicadores de desempenho não podem ser padronizados, ou seja, cada organização deve definir os indicadores de desempenho que serão utilizados, sempre tendo como objetivo principal a sua real necessidade. A implementação de indicadores adequados aos objetivos da organização leva em consideração o estabelecimento de padrões para a sua avaliação, permitindo assim que estes indicadores se tornem um instrumento de implementação de melhorias.

Dentro do processo de implementação do sistema de medição por meio de indicadores de desempenho em uma empresa, deve-se deixar claro a todas as pessoas envolvidas que o monitoramento serve para mostrar-lhes como o trabalho está sendo realizado e assim poder adotar medidas corretivas para que estes sejam constantemente aperfeiçoados. Assim, é de fundamental importância que todas as pessoas que compõem a organização entendam e incorporem os indicadores ao seu trabalho. A utilização de indicadores de desempenho vai muito além do fato de apenas medirmos o que é realizado, para se constituir em uma ferramenta completa que permite a implementação de melhorias, reduzindo o tempo que vai desde a coleta dos dados e a efetiva 
implantação das medidas necessárias para conduzir todo o processo a um grau maior de satisfação do cliente, seja ele, interno ou externo.

A Gestão da Produção carece de metodologias e técnicas de fácil entendimento e aplicação prática. A metodologia proposta neste trabalho vem ajudar a preencher esta lacuna.

\begin{abstract}
Lean Manufacturing (LM) is a management paradigm which aims waste reduction. Although LM is well known and related to performance improvement, there is a discussion on production management literature about considering LM as the best practice. So it is necessary to evaluate LM capacity on bringing competitiveness improvement for companies. This is the main contribution of this paper, once it proposes an unpublished methodology based on lean performance indicators (the majority of traditional performance indicators are not indicated to measure LM performance) to evaluate LM implementation. The methodology facilitates workers commitment and the success of the LM implementation. The methodology helps company choosing LM performance indicators based on three main characteristics: LM implementation goals; LM implementation comprehension (shop floor, company or supply chain); and implementation level of LM principles. The methodology is put into practice into a large company that produces medical-hospital equipments and instruments.
\end{abstract}

Key Words: Lean Manufacturing, evaluation of implementation, performance indicators, case study, medical-hospital equipments

\title{
Referências Bibliográficas
}

ALLEN, J.H. - Make lean manufacturing work for you. Manufacturing Engineering, vol. 6, pp. 54-64, 2000.

BAMBER, L. and DALE, G. - Lean production: a study of application in a traditional manufacturing environment. Production Planning \& Control, Vol.11, n 3, pp.291-298, 2000.

DETTY, R.B.; YINGLING, J.C. - Quantifying benefits of conversion to lean manufacturing with discrete event simulation: a case study. International Journal of Production Research, v.38, n.2, 429-445, 2000.

crossef

DIAS, F.T. (2003) - Proposta de uma metodologia baseada em indicadores de desempenho para avaliação de princípios relativos à Produção Enxuta. Dissertação de Mestrado. Universidade Federal de São Carlos. São Carlos.

EISENHARDT, K.M. - Building theories form case study research, Academy of Management Review, vol. 14, $\mathrm{N}^{\mathrm{0}} 4$, 532-550, 1989.

crossef

FERNANDES, F.C.F.; MACCARTHY, B.L. - Production planning and control: the gap between theory and practice in the light of modern manufacturing concepts. In: $15^{\mathrm{TH}}$ INTERNATIONAL CONFERENCE ON CAD/CAM, ROBOTICS \& FACTORIES OF THE FUTURE (CARS \&FOD'99), Águas de Lindóia. Proceedings of the 15 ${ }^{\text {th }}$ International conference on CAD/CAM, Robotics \& Factories of the Future (CARS \&FOD'99), v.1, p.1-6, 1999.

GALBRAITH, L. \& STANDRIDGE, C.R.: Analysis in Manufacturing Systems simulation - a case study. Simulation, vol. 63 , pp. 368-375, 1994.

cross ${ }^{\text {ref }}$ 
GODINHO FILHO, M. - Paradigmas Estratégicos de Gestão da Manufatura - configuração, relações com o Planejamento e Controle da Produção e estudo exploratório na indústria de calçados. Tese de Doutorado - Universidade Federal de São Carlos. São Carlos, 2004.

GODINHO FILHO, M. \& FERNANDES, F.C.F. Manufatura Enxuta - uma revisão que classifica e analisa os trabalhos apontando perspectivas de pesquisas futuras. Revista Gestão \& Produção, vol. 11, n.1, pp.1-19, 2004.

KARLSSON, C.; AHLSTRÖM, P. - Assessing changes towards lean production. International Journal of Operations \& Production Management, v.16,n.2, p.24-41, 1996.

cross'

LEWIS, M.A. - Lean Production and sustainable competitive advantage. International Journal of Operations \& Production Management, Vol. 20, nº 8, pp.959-978, 2000.

LUMMUS, R.: A simulation analysis of sequencing alternatives for JIT lines using kanbans. Journal of Operations Management, vol. 13, pp. 183-191, 1995.

cross ${ }^{\text {ref }}$

MACCARTHY, B.L.; LIU, J. - Addressing the gap in scheduling research - a review of optimization and heuristic methods in production scheduling. International Journal of Production Research, vol. 31, n.1, pp.59-79, 1993.

crossef

MARTINS, R.A.; COSTA NETO, P.L.O. - Indicadores de desempenho para a gestão pela qualidade total: uma proposta de sistematização. Revista Gestão \& Produção, v.5, n.3, p.298-311, 1998.

NAM, S.; LOGENDRAN, R. - Aggregate Production Planning - a review of models and methodologies. European Journal of Operational Research, vol. 61, pp. 255-272, 1992.

cross ${ }^{\text {ref }}$

NEELY, A. - The performance measurement revolution: why now and what next? International Journal of Operations \& Production Management. v.19, n.2, p.205-228, 1999.

crossef

OLIVER, N.; DELBRIDGE, R.; LOWE, J. - Lean Production Practices: International Comparisons in the Auto Components Industry. British Journal of Management, vol.7, special issue, pp. S29-S44, 1996.

cross ${ }^{\text {ref }}$

PANIZZOLO, R. - Applying the lessons learned from 27 lean manufacturers. The relevance of relationships management. International Journal of Production Economics, vol. 55, pp.223-240, 1998.

crossef

SÁNCHEZ, A.M.; PÉREZ, M.P. - Lean indicators and manufacturing strategies. International Journal of Operations \& Production Management. V.21, n.11, p.1433-1451, 2001.

cross ${ }^{\text {ref }}$

SCHMENNER, R.W.; VOLLMANN, T.E. - Performance measures: gaps, false alarms and the "usual suspects". International Journal of Operations \& Production Management. v.14, n.12, p.58-69, 1994

cross ${ }^{\text {eef }}$.

WOMACK, J.P. \& JONES, D.T. - A Mentalidade Enxuta nas Empresas. Ed. Campus, 5º Edição, 1998.

\section{Dados dos autores}

$\underline{\text { Flavio Teodoro Dias }}$

Mestre em Engenharia de Produção pela Universidade Federal de São Carlos

Gerente de Planejamento e Controle da Produção da Braile Biomédica S/A 
Av. Presidente Juscelino K. Oliveira, 1505 - São José do Rio Preto - SP

Tel: 0xx(17) 21367000 email: flavio@braile.com.br

\section{$\underline{\text { Flavio Cesar Faria Fernandes }}$}

Pós-Doutor em PCP pela The University of Notthinghan

Doutor em Engenharia pela Escola de Engenharia de São Carlos da Universidade de São Paulo Mestre em Engenharia de Produção pela Escola Politécnica da Universidade de São Paulo

Professor Associado - Universidade Federal de São Carlos

Departamento de Engenharia de Produção - Programa de Pós-Graduação

Rod. Washington Luís, Km 235 - CEP 13565-905 São Carlos - SP

Tel. 0xx1633518237 ramal 9514 email: dfcf@power.ufscar.br

\section{Moacir Godinho Filho}

Pós Doutorado em aplicação de System Dynamics e Factory Physics em sistemas de Produção na North Carolina State University

Pós Doutorado em Quick Response Manufacturing na University of Wisconsin at Madison

Doutor em Engenharia de Produção pela Universidade Federal de São Carlos

Mestre em Engenharia de Produção pela Universidade Federal de São Carlos

Professor Adjunto nível II - Universidade Federal de São Carlos

Departamento de Engenharia de Produção - Programa de Pós-Graduação

Rod. Washington Luís, Km 235 - CEP 13565-905 São Carlos - SP

Tel.0xx16 33518237 ramal 9507 e-mail: moacir@dep.ufscar.br 